Research Paper:

\title{
Relationship Between Health-Promoting Behaviors and crossuark Quality of Life in Postmenopausal Women
}

\author{
Amine Alaeenejad ${ }^{1}$, Marhamat Farahaninia ${ }^{1 *} \mathcal{O}$, Sara Janmohammadi ${ }^{1}$, Hamid Haghani ${ }^{2}$
}

1. Department of Community Health Nursing, School of Nursing and Midwifery, Iran University of Medical Sciences, Tehran, Iran.

2. Department of Biostatistics, School of Public Health, Iran University of Medical Sciences, Tehran, Iran.

\begin{tabular}{|c|c|}
\hline $\begin{array}{l}\text { Use your device to scan } \\
\text { and read the article online }\end{array}$ & 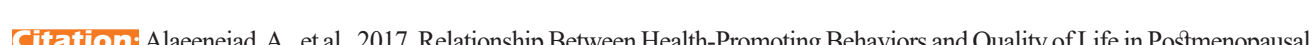 \\
\hline 口品唯回 & Women. Journal of Client-Centered Nursing Care, 3(4), pp. 269-276. https://doi.org/10.32598/jccnc.3.4.269 \\
\hline 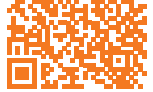 & doi': https://doi.org/10.32598/jccnc.3.4.269 \\
\hline
\end{tabular}

Article info:

Received: 08 Mar 2017

Accepted: 12 Jul 2017
Keywords:

Health promotion

behaviors,

Postmenopausal women,

Quality of life, Tehran,

Iran

\begin{abstract}
A B S T RA C T
Background: Menopause is one of the most important stages of women's life in the path of development which, comes with a series of other problems. The health status and quality of life issues of the postmenopausal women are serious challenges for many health areas. The aim of this study was to determine the relationship between health promotion behaviors and the quality of life of postmenopausal women.
\end{abstract}

Methods: This descriptive-correlational study was performed on 200 postmenopausal women in the west of Tehran. The armamentarium for this study was a three-part questionnaire comprising demographic data, the second version of Health Promoting Lifestyle Profile (HPLP II) and Menopause-Specific Quality of Life (MENQOL). Data were analyzed by descriptive and inferential statistical tests using SPSS V. 20.

Results: The results showed that the mean score of health promotion behaviors was $2.49 \pm 0.47$ (in moderate level). More than half of the participants had a good quality of life, an overall quality of life mean score being $70.63 \pm 37.49$. The overall score of health promotion behaviors and quality of life was better in women who were married, younger aged, with good economic status, employment and those who achieved higher education.

Conclusion: The results of Pearson correlation test showed that there is a significant reverse correlation between quality of life and health promotion behaviors in the stress management dimension ( $\mathrm{P}=$ 0.013). Therefore educational programs are recommended as an effective, economical and safe approach to reducing the menopause problems and augmenting the quality of life.

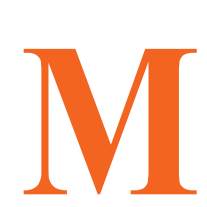

\section{Background}

enopause is a global phenomenon

(Hess et al. 2011) and a process that in-

creases individual pressure on women by reducing estrogen. This natural process which is associated with biophysical, mental and social changes, as well as personal experiences, is very annoying for them (Sorpreso et al. 2015). In this period the loss of hormonal balance, especially estrogen loss, can cause sleep disor-

* Corresponding Author:

Marhamat Farahaninia, MSc.

Address: Department of Community Health Nursing, School of Nursing and Midwifery, Iran University of Medical Sciences, Tehran, Iran.

Tel: +98 (21) 43651806

E-mail: farahaninia.m@iums.ac.ir 
ders, night sweats, headache, hot flashes, vaginal dryness, anger, depression, increased cholesterol and heart diseases (Williams et al., 2009). The results of the studies indicate a negative effect of menopausal symptoms on women's quality of life (Speroff \& Fritz 2005; Hess et al. 2011; Ceylan \& Özerdoğan 2014). This period, like all other stages of life, has positive aspects also such as feeling free from pregnancy problems as well as negative aspects such as the dangers and health threats to the women (Im et al. 2010).

The average increase in the life expectancy and decrease in the mortality have led to an increase in the age of the global population, while women spend one-third of their lives in menopause (Cavadas et al. 2010). Considering the increasing population of the world, it is estimated that the population of women aged over 50 years in the world will reach 1.2 billion by 2030 (Cavadas et al. 2010). The statistics of postmenopausal women in Iran will reach around 5 million by 2021 and life expectancy is over 70 years. So, on the eve of the third millennium, menopause is the center of attention for many medical and health communities and has been raised as a major health and social problem in different countries (Mohammadi Zeidi, Pakpour \& Mohammadi Zeidi 2013). On the other hand, it is a globally accepted fact that health and welfare of the societies are determined by many factors outside the health system (Kumar \& Preetha 2012), most of which is the promotion of health and lifestyle improvement (Nazari et al. 2016). According to the World Health Organization, $60 \%$ of people's quality of life depends on their attitude and lifestyle (Mirghafourvand et al. 2017), such that $70-80 \%$ of deaths in the developed countries and 50 $60 \%$ in the developing countries are related to lifestyle (Rakhshan et al. 2014). Scientific evidences suggest that the choice of lifestyle influences health and longevity of the people (Toledo et al. 2007).

The lifestyle is the usual daily activity that people have accepted it in their lives, it affects the health of individuals, their quality of life and the capacity for the prevention of illness (Rakhshan et al. 2014). Promoting lifestyle-related behaviors will lead to maintaining the function and independence of individuals, improving their quality of life and reducing their health care costs (Hajizadeh et al. 2016). The lifestyle with demographic factors or socioeconomic status is very determinative of population's health conditions (Makara et al. 2015). Therefore, the importance of health promotion behaviors with emphasis on healthy lifestyle as a key strategy for maintaining, improving good quality of life and reducing the cost of treatment has been considered (Rakhshan et al. 2014; Sehhatie et al., 2015). The health status and quality of life associated with postmenopausal women, nowadays, are a serious challenge for many scientific fields (Jasińska et al., 2014).

Reduced quality of life in this period can be due to social, demographic factors (such as age, smoking, educational level) and loss of mobility (Karaçam and Şeker, 2007). According to MaKara et al. (2014), the prevalence of menopausal symptoms is more pronounced in African women. In South America, the symptoms are connected with depression, sexual dysfunction and muscular pain. In Australia, complaints of the motor system and sexual dysfunction; in Europe, sleep disorders and depression; and in Asia, increased risk of depression were reported. According to the studies and different results regarding the relationship between health-promotion behaviors and quality of life of general population (not primarily among postmenopausal women), and the lack of studies on health promotion behaviors and the quality of life of postmenopausal women, this paper aimed to investigate the relationship between health-promoting behaviors and quality of life in postmenopausal women referred to health centers in west of Tehran, Iran.

\section{Materials and Methods}

In this descriptive/correlational study, the statistical population consists of postmenopausal women in West Tehran health centers, whose menstruation was at least 6 months ago and have not gone under hormonal therapy and/or hysterectomy. West Tehran health centers included 10 centers. First, the researcher collected the statistics on the number of postmenopausal women from each center and then divided the sample size into the proportion of patients. In this regard, 200 samples were selected from five centers based on convenience sampling method. After explaining the goals of the research and obtaining written consent, guidance and explanation about the completion of the questionnaire were given to participants, and then the data were collected after completion. The questionnaire had three sections; first section surveyed demographic characteristics including age, marital status, educational status, occupation, financial status, number of children and the duration of menopause; second section measured health-promoting behavior using the second version of Health Promoting Lifestyle Profile (HPLP II) tool; and the third section asked about the quality of life of participants by employing MenopauseSpecific Quality of Life (MENQOL) instrument.

HPLP II instrument covers six dimensions of healthpromoting behaviors: Nutrition (7 items), Physical activity (6 items), Health responsibility (14 items), Stress 
management (5 items), Interpersonal relations (8 items), and Spiritual growth (9 items). Each question is scored on a four-point Likert scale (1: Never, 2: Sometimes, 3: Often, and 4: Routinely). The overall score is calculated based on the mean score of the responses to all items. Higher scores in each dimension indicate the positive frequency of health-promoting behavior and lower scores show negative frequency.

MENQOL instrument had 31 items covering four dimensions including vasomotor (items 1-3), psychosocial (items 4-12), physical (items 13-27) and sexual (items 28-31). The items indicating a specific symptom are rated based on a six-point Likert scale (1: Never, 2: Partially, 3: To some extent, 4: Moderately, 5: Very, 6: Extremely). It should be noted that the researcher re-examined the validity and reliability of the two instruments. The content validity method was used to determine the validity. In this regard, the questionnaires were examined by 10 professors of the Faculty of Nursing and Midwifery in Iran University of Medical Sciences. For testing the reliability of instruments, internal consistency and test-retest techniques were used. Internal consistency method was conducted on 20 samples and Cronbach's alpha was ob- tained as 0.971 . Two weeks later, the study questionnaire was again distributed to the same 20 samples and the reliability coefficient was calculated in two steps, which was obtained as 0.83 . After the evaluation, these 20 participants were excluded from the study. Calculations and results were analyzed using descriptive data (frequency, mean, percentage, standard deviation) and inferential statistics (ANOVA, independent t-test and Kruskal-Wallis nonparametric test) in SPSS V 20 software.

\section{Results}

Descriptive statistics showed that $59 \%$ of women had the menopause symptoms more than five years ago; $28 \%$ were under 50 years old; and the mean age of the studied participants was 58.16 with a standard deviation of 12.85. The majority of participants were at the middleschool educational level and $88 \%$ were housewives with a relatively good economic condition. Also, $44 \%$ of them had 4 to 6 children while $71 \%$ were married.

The results showed that the mean score of health-promoting behaviors was 2.49 with a standard deviation of 0.47 which was moderate. Among the dimensions of health-promoting behaviors, the highest mean was relat-

Table 1. Statistics of health-promoting behaviors and its dimensions among participants

\begin{tabular}{|c|c|c|c|c|}
\hline Dimensions of Health Promoting Behaviors & Min & Max & Mean & SD \\
\hline Nutrition & 1 & 3.29 & 2.16 & 0.49 \\
\hline Physical activity & 1.17 & 4.33 & 2.61 & 0.69 \\
\hline Health responsibility & 1 & 3.71 & 2.26 & 0.59 \\
\hline Stress management & 1.4 & 4.6 & 2.88 & 0.75 \\
\hline Interpersonal relations & 1.38 & 4.5 & 2.81 & 2.68 \\
\hline Spiritual growth & 1.11 & 4.33 & 2.53 & 0.88 \\
\hline Health promoting behaviors & 1.53 & 4 & 2.49 & 0.47 \\
\hline
\end{tabular}

Table 2. Statistics of the quality of life and its dimensions among participants

\begin{tabular}{|c|c|c|c|c|}
\hline Dimensions of the Quality of Life & Min & Max & Mean & SD \\
\hline Vasomotor & 3 & 18 & 6.51 & 4.5 \\
\hline Psychosocial & 9 & 54 & 21.24 & 11.46 \\
\hline Physical & 15 & 87 & 35.06 & 20.09 \\
\hline Sexual & 4 & 24 & 7.81 & 6.02 \\
\hline Quality of life & 31 & 173 & 70.63 & 37.45 \\
\hline
\end{tabular}


Table 3. Correlation results between health-promoting behaviors and the quality of life

\begin{tabular}{|c|c|c|c|c|c|c|c|c|}
\hline Correlation & & Nutrition & $\begin{array}{l}\text { Physical } \\
\text { Activity }\end{array}$ & $\begin{array}{c}\text { Health } \\
\text { Responsibility }\end{array}$ & $\begin{array}{c}\text { Stress } \\
\text { Management }\end{array}$ & $\begin{array}{l}\text { Interpersonal } \\
\text { Relations }\end{array}$ & $\begin{array}{l}\text { Spiritual } \\
\text { Growth }\end{array}$ & $\begin{array}{l}\text { Health } \\
\text { Promoting } \\
\text { Behaviors }\end{array}$ \\
\hline \multirow{2}{*}{ Vasomotor } & $\mathrm{R}$ & 0.033 & -0.081 & -0.026 & -0.05 & 0.065 & 0.077 & 0.029 \\
\hline & $\mathrm{P}$ & 0.640 & 0.253 & 0.714 & 0.478 & 0.362 & 0.277 & 0.681 \\
\hline \multirow{2}{*}{ Psychosocial } & $\mathrm{R}$ & -0.047 & -0.079 & -0.051 & -0.169 & -0.031 & 0.012 & -0.116 \\
\hline & $\mathrm{P}$ & 0.507 & 0.267 & 0.477 & 0.017 & 0.658 & 0.87 & 0.101 \\
\hline \multirow{2}{*}{ Physical } & $\mathrm{R}$ & 0.052 & 0.020 & 0.055 & -0.185 & 0.023 & 0.14 & -0.021 \\
\hline & $\mathrm{P}$ & 0.466 & 0.784 & 0.439 & 0.009 & 0.743 & 0.048 & 0.765 \\
\hline \multirow{2}{*}{ Sexual } & $\mathrm{R}$ & 0.187 & 0.199 & 0.108 & -0.112 & 0.159 & 0.199 & 0.136 \\
\hline & $\mathrm{P}$ & 0.008 & 0.005 & 0.129 & 0.114 & 0.024 & 0.005 & 0.056 \\
\hline \multirow{2}{*}{ Quality of life } & $\mathrm{R}$ & 0.048 & -0.012 & 0.028 & -0.175 & 0.036 & 0.12 & -0.022 \\
\hline & $\mathrm{P}$ & 0.504 & 0.862 & 0.691 & 0.013 & 0.610 & 0.091 & 0.760 \\
\hline
\end{tabular}

ed to stress management and the lowest mean was for nutrition (Table 1). Moreover, the mean score for the quality of life was 7.63 with a standard deviation of 37.45 which indicated the good quality of life of the participants (Table 2). The results of Pearson correlation test showed that the quality of life had a negative significant correlation with health-promoting behaviors only in terms of stress management; i.e. the higher the stress management score, the better the quality of life would be (Table 3 ).

Results of the study also showed that there was a significant relationship between health-promoting behaviors and age of participants $(\mathrm{P}<0.001)$. Scheffe post hoc test results indicated that the difference was in the age group of "70 years and older" with the groups of "less than 50 years" ( $\mathrm{P}<0.001)$ and "50-59 years" $(\mathrm{P}=0.008)$. Also, this difference was significant in both groups of "60-69 years" and "less than 50 years" $(\mathrm{P}=0.037)$. Kruskal Wallis test showed that the marital status $(\mathrm{P}=0.047)$ and educational status $(\mathrm{P}<0.001)$ also had a statistically significant relationship with health-promoting behaviors. Pairwise comparison showed that the health-promoting behaviors in singles was significantly higher than the widows $(\mathrm{P}=0.020)$. Moreover, in postmenopausal women with academic degree, health-promoting behaviors were significantly higher $(\mathrm{P}<0.001)$. Independent T-test results indicated that the health-promoting behaviors were significantly higher among employed postmenopausal women than those who were housewives ( $\mathrm{P}$ $<0.001)$. Financial status was another variable that had a significant relationship with health-promoting behaviors
$(\mathrm{P}=0.005)$. Scheffe and Pairwise comparison results showed that the health-promoting behaviors in postmenopausal women with an unfavorable financial status were significantly lower than others. With respect to the quality of life of participants, the ANOVA results indicated that educational status had a significant relationship with quality of life $(\mathrm{P}=0.043)$. Pairwise comparison results showed that the quality of life in postmenopausal women with middle-school educational level was better than that of others $(\mathrm{P}=0.004)$. Financial status was another variable that had a significant relationship with the quality of life $(\mathrm{P}=0.003)$. Results of Scheffe and Pairwise comparison showed that the quality of life in postmenopausal women with an unfavorable financial situation was significantly different and lower than that of others (Table 4).

\section{Discussion}

The results of this study showed that the mean score of health-promoting behaviors among postmenopausal women was 2.49 with a standard deviation of 0.47 (which was moderate). Also, the mean score of quality of life was 70.63 with a standard deviation of 37.45 . The average score of health promotion and quality of life behaviors in married, younger, and employed postmenopausal women with favorable financial status and higher educational level was higher. According to the results of this study, the quality of life of postmenopausal women had a negative significant relationship with health promotion behaviors only in terms of stress management. 
Table 4. Statistics of health-promoting behaviors and the quality of life based on demographic characteristics

\begin{tabular}{|c|c|c|c|c|c|c|c|}
\hline \multirow{2}{*}{\multicolumn{2}{|c|}{ Demographic Characteristics }} & \multicolumn{3}{|c|}{ Health Promoting Behaviors } & \multicolumn{3}{|c|}{ Quality of Life } \\
\hline & & Mean & SD & Test Result & Mean & SD & Test Result \\
\hline \multirow{4}{*}{ Age } & $<50$ & 2.61 & 0.51 & \multirow{4}{*}{$P<0.001^{* *}$} & 69.53 & 39.45 & \multirow{4}{*}{$P=0.094^{* *}$} \\
\hline & $50-59$ & 2.48 & 19.92 & & 67.04 & 34.42 & \\
\hline & $60-69$ & 2.37 & 22.26 & & 81.26 & 40.44 & \\
\hline & $>70$ & 2.16 & 14.35 & & 63.19 & 32.42 & \\
\hline \multirow{3}{*}{ Marital status } & Married & 2.47 & 23.68 & \multirow{3}{*}{$P=0.047^{\# \#}$} & 73.62 & 39.63 & \multirow{3}{*}{$P=0.402^{\# \#}$} \\
\hline & Single & 2.52 & 0.43 & & 60.5 & 28.47 & \\
\hline & Widow & 2.25 & 0.48 & & 61 & 21.48 & \\
\hline \multirow{3}{*}{$\begin{array}{l}\text { Educational } \\
\text { status }\end{array}$} & Unlettered/primary school & 2.25 & 0.36 & \multirow{3}{*}{$P<0.001^{\# \#}$} & 79.42 & 41.58 & \multirow{3}{*}{$P=0.043^{\# \#}$} \\
\hline & Middle school & 2.43 & 0.45 & & 61.29 & 27.96 & \\
\hline & Academic & 3.18 & 0.42 & & 80.38 & 50.24 & \\
\hline \multirow[b]{2}{*}{ Occupation } & Housewife & 2.35 & 0.43 & \multirow[b]{2}{*}{$\mathrm{P}<0.001^{*}$} & 69.31 & 35.63 & \multirow[b]{2}{*}{$P=0.295^{*}$} \\
\hline & Employed & 2.92 & 0.59 & & 80.29 & 48.6 & \\
\hline \multirow{3}{*}{$\begin{array}{l}\text { Number of } \\
\text { children }\end{array}$} & $1-3$ & 2.40 & 0.55 & \multirow{3}{*}{$P=0.692^{*} *$} & 66.27 & 32.98 & \multirow{3}{*}{$P=0.462 * *$} \\
\hline & $4-6$ & 2.46 & 0.44 & & 72.65 & 37.65 & \\
\hline & $>7$ & 2.38 & 0.44 & & 74 & 44.23 & \\
\hline \multirow{3}{*}{ Financial status } & Unfavorable & 2.14 & 0.36 & \multirow{3}{*}{$P=0.005^{*} *$} & 99 & 48.62 & \multirow{3}{*}{$P=0.003^{*} *$} \\
\hline & Relatively favorable & 2.42 & 0.50 & & 69.66 & 35.76 & \\
\hline & Favorable & 2.53 & 0.45 & & 60.58 & 29.67 & \\
\hline \multirow{3}{*}{$\begin{array}{l}\text { Duration of } \\
\text { menopause }\end{array}$} & 6 months to 1 year & 2.41 & 0.60 & & 64.49 & 33.05 & \multirow{3}{*}{$P=0.397^{\# \#}$} \\
\hline & $1-5$ year & 2.39 & 0.43 & $P=0.549^{\# \#}$ & 64.54 & 28.81 & \\
\hline & $>5$ year & 2.43 & 0.44 & & 74.88 & 40.75 & \\
\hline
\end{tabular}

In the present study, the mean score of health-promoting behaviors was moderate which is consistent with the results of Sehhatie et al. (2015). In this study, the participants had the highest mean score of stress management and the lowest mean score of nutrition, while in the study of Sehhatie et al. the highest score was related to spiritual growth and the lowest score was related to physical activity. The results of Shabani et al. (2016) did not show any difference in any dimensions. According to Cavadas et al. (2010), the factors that influence the health promotion behaviors of postmenopausal women include financial status, education, interpersonal relations, situational factors and demographic variables. In terms of financial status, education and interpersonal relations their results are consistent with the results of current research.

The results of the previous studies show the negative impact of menopausal symptoms on women's quality of life (Ceylan \& Özerdoğan 2014; Hess et al. 2011). In this regard, the results of Kalarhoudi et al. (2011) showed that only $17.9 \%$ of participated women had an overall good quality of life and housewives had a better quality of life which is against the results of our study, but the level of education, physical activities and financial status were factors related to the quality of life of women during menopause; these results are similar to the results of 
the current study. A study in Turkey also showed that the quality of life of postmenopausal women is significantly correlated with age, income, educational level and body mass index (Ceylan \& Özerdoğan 2014) which is consistent with our results.

Williams et al. (2009) showed that menopausal women with university degree and job had a higher quality of life. This also supports our results. Rakhshani et al. (2014) study also supported the results of this study in terms of educational level and marital status. Mohamed, Lamadah \& Zamil (2017) indicated the negative impact of menopause on women's quality of life in all dimensions which is in agreement with the present study. Results of Lee \& Kim (2008) also indicated the positive effects of physical activity on menopausal symptoms, physical and mental health and the quality of life. In examining the relationship between the severity of menopausal symptoms and depression with physical activity, they found out that women who were exercising more than three times a week had fewer symptoms and depression than women who did not exercise and their quality of life score was better. According to Elavsky and McAuley (2009), a 4 month intervention involving walking and yoga can reduce menopausal symptoms such as psychological, stress, vasomotor and sexual complaints. Although there is no intervention in our study, but the effect of stress management and physical activity on the quality of life has been identified. Beliran and Legaspi (2014) showed that in overall, health-promoting behavior was at low level and the quality of life was moderate; age, monthly income of the family and the health of the individuals had a significant association with the healthpromoting behaviors and quality of life, which are consistent with the results of present research.

It this study it was concluded that the mean score of health-promoting behaviors was moderate and more than half of postmenopausal women with a good mean score had a good quality of life. Mean score of health-promoting behaviors and the quality of life was better among married, younger, employed postmenopausal women with favorable financial status and higher educational level. The results of Pearson correlation test showed that quality of life had a negative significant correlation with health-promoting behaviors only in terms of stress management, i.e., the higher the stress management score, the better the quality of life will be. Therefore, an effective, safe and budget-friendly plan is recommended by designing and implementing educational programs for reducing postmenopausal problems, especially stress management in order to increase the quality of life of postmenopausal women.

\section{Acknowledgments}

This research did not receive any specific grant from funding agencies in the public, commercial, or not-forprofit sectors. This paper was extracted from a MSc. thesis approved by Iran University of Medical Sciences (license No.: IR.IUMS.REC 1395.9211196252). The authors would like to thank Research Deputy, health centers, study participants and all those who helped us in conducting this research.

\section{Conflict of Interest}

The authors declared no conflict of interest.

\section{References}

Asrami, F. S., Hamzehgardeshi, Z. \& Shahhosseini, Z., 2016 Health promoting lifestyle behaviors in menopausal women: A cross-sectional study. Global journal of health science, 8(8) pp. 128-34. [DOI:10.5539/gihs.v8n8p128]

Beliran, S. P. \& Legaspi, M. S., 2014. Health-promoting behaviors and quality of life of Filipino older persons. Asia Pacific Journal of Education, Arts and Sciences, 1(5), pp. 11-20.

Cavadas, L. F., et al., 2010. Management of menopause in primary health care. Acta medica Portuguesa, 23(2), pp. 227-36. [PMID]

Ceylan, B. \& Özerdoğan, N., 2014. Menopausal symptoms and quality of life in Turkish women in the climacteric period. Climacteric, 17(6), pp. 705-12. [DOI:10.3109/13697137.2014.9291 08]

Elavsky, S. \& McAuley, E., 2009. Personality, menopausal symptoms, and physical activity outcomes in middle-aged women. Personality and Individual Differences, 46(2), pp. 123-8. [DOI:10.1016/j.paid.2008.09.014]

Hajizadeh Sharafabad, F. \& Alizadeh, M., 2016. Predictors of health-promoting behaviors in patients with coronary artery disease in the Iranian population. International Journal of Nursing Practice, 22(5), pp. 486-92. [DOI:10.1111/ijn.12459]

Hess, R. et al., 2011. The impact of menopause on health-related quality of life: Results from the STRIDE longitudinal study. Quality of Life Research, 21(3), p. 535-44. [DOI:10.1007/ s11136-011-9959-7]

Im, E. O. et al., 2010. A national multiethnic online forum study on menopausal symptom experience. Nursing Research, 59(1), pp. 26-33. doi: 10.1097/nnr.0b013e3181c3bd69 [DOI:10.1097/ NNR.0b013e3181c3bd69]

Jasińska, M. et al., 2014. Health behaviors of postmenopausal women. Menopausal Review, 1, pp. 22-6. [DOI:10.5114/ pm.2014.41083]

Kalarhoudi, M. A., et al., 2011. Assessment of quality of life in menopausal periods: a population study in Kashan, Iran. Ira- 
nian Red Crescent Medical Journal, 13(11), pp. 811-7. PMCID: PMC3371893

Karaçam, Z. \& Şeker, S. E., 2007. Factors associated with menopausal symptoms and their relationship with the quality of life among Turkish women. Maturitas, 58(1), pp. 75-82. [DOI:10.1016/j.maturitas.2007.06.004]

Kumar, S. \& Preetha, G., 2012. Health promotion: An effective tool for global health. Indian Journal of Community Medicine, 37(1), p. 5. [DOI:10.4103/0970-0218.94009]

Lee, Y. \& Kim, H., 2008. Relationships between menopausal symptoms, depression, and exercise in middle-aged women: A cross-sectional survey. International Journal of Nursing Studies, 45(12), pp. 1816-22. [DOI:10.1016/j.jinurstu.2008.07.001]

Makara Studzińśka, M. T., Kryś-Noszczyk, K. M. \& Jakiel, G., 2014. Epidemiology of the symptoms of menopause: An intercontinental review. Menopausal Review, pp. 203-11. [DOI:10.5114/pm.2014.43827]

Makara Studzińska, M., Kryś Noszczyką, K. \& Jakiel, G., 2015 The influence of selected socio-demographic variables on symptoms occurring during the menopause. Menopausal Review, 1, pp. 20-6. [DOI:10.5114/pm.2015.48637]

Mirghafourvand, M. et al., 2017. Relationship between healthpromoting lifestyle and quality of life in women with polycystic ovarian syndrome. International Journal of Women's Health and Reproduction Sciences, 5(4), pp. 318-23. [DOI:10.15296/ijwhr.2017.54]

Mohamed, H. A., Lamadah, S. M. \& Zamil, L. G. A., 2017. Quality of life among menopausal women. International Journal of Reproduction, Contraception, Obstetrics and Gynecology, 3(3), pp. 552-61

Mohammadi Zeidi, E., Pakpour, A. \& Mohammadi Zeidi, B., 2013. The impact of educational interventions based on individual empowerment model on knowledge, attitude, selfefficacy, self esteem and quality of life of postmenopausal women. Iran Journal of Nursing, 26(81), pp. 21-31.

Nazari, M. et al., 2016. The effectiveness of lifestyle educational program in health promoting behaviors and menopausal symptoms in 45-60-year-old women in Marvdasht, Iran. Global Journal of Health Science, 8(10), p. 34. [DOI:10.5539/ gihs.v8n10p34]

Rakhshani, T. et al., 2014. The association of health-promoting lifestyle with quality of lfe among the Iranian elderly. Iranian Red Crescent Medical Journal, 16(9). [DOI:10.5812/ ircmj.18404]

Sehhatie, F., Mirghafourvand, M. \& Momeni, K., 2015. Health promoting behaviors among postmenopausal women in Langroud City, Iran. International Journal of Women's Health and Reproduction Sciences, 3(3), pp. 158-62. [DOI:10.15296/ ijwhr.2015.33]

Shabani Asrami, F., Hamzehgardeshi, Z. \& Shahhossein, Z. 2016. Health Promoting Lifestyle Behaviors in Menopausal Women: A Cross-Sectional Study. Global Journal of Health Science, 8(8), pp. 128-13. [DOI:10.5539/gjhs.v8n8p128]

Sorpreso, I. C. E. et al., 2015. Female aging. Revista da Associação Médica Brasileira, 61(6), pp. 553-6. [DOI:10.1590/18069282.61.06.553]
Speroff, L. \& Fritz, M. A. eds., 2005. Clinical gynecologic endocrinology and infertility. Philadelphia: Lippincott Williams \& Wilkins.

Toledo, F. G. S. et al., 2007. Effects of physical activity and weight loss on skeletal muscle mitochondria and relationship with glucose control in type 2 diabetes. Diabetes, 56(8), pp. 2142-7. [DOI:10.2337/db07-0141]

Williams, R. E. et al., 2009. Menopause-specific questionnaire assessment in US population-based study shows negative impact on health-related quality of life. Maturitas, 62(2), pp. 153-9. [DOI:10.1016/j.maturitas.2008.12.006] 
November 2017. Volume 3. Number 4

Client-Centered Nursing Care

276 